\title{
Entre Metáforas e Epifanias: A (Trans)Formação de Identidades em Sergio Y. vai à América
}

\author{
LIDIANA DE MORAES
}

University of Miami

\begin{abstract}
In the present essay, I argue that despite the conservative ideals espoused by the narrator of Alexandre Vidal Porto's Sergio Y. vai à América (2014), it is precisely within these conflictive and contradicting thoughts that one finds a critique of heteronormativity. In other words, while Vidal Porto seems not to address problems regularly addressed in the field of queer and gender studies, his omission of queer performativity and any empowering discourse for the transgender community is a strategy he employs to interrogate how conservative societies such as Brazil define sex, sexual identity, social practices, and queer space.
\end{abstract}

Keywords: LGBTQ representations, transsexuality, Brazil, immigration, Alexandre Vidal Porto

Na contracapa de Sergio Y. vai à América, Luiz Ruffato celebra o trabalho de Alexandre Vidal Porto por sua coragem ao enfrentar um tema-tabu: a transexualidade. No entanto, a narrativa de Vidal Porto não aborda o assunto de forma escancarada, fazendo perguntas e dando respostas diretas para um tópico que muitos brasileiros ainda desconhecem ou sobre o qual têm um conhecimento precário, às vezes cercado por preconceitos equivocados.

Em uma resenha do texto no jornal $O$ Globo, Elias Fajardo define o livro como um "olhar delicado sobre escolhas difíceis," e salienta que uma de suas 
maiores qualidades é justamente como o autor conseguiu "se sair bem principalmente porque usa sutileza e delicadeza para contar a história de Sergio." A resenha de Fajardo não está errada; porém, há sutileza em excesso em Sergio $Y$. Para "se sair bem," Vidal Porto usa um olhar heteronormativo sobre um tema que transcende as barreiras impostas pelo conservadorismo. Não há nada de queer, revolucionário ou vanguardista na forma como o autor fala sobre Sergio, um rapaz transgênero. ${ }^{1}$ Por mais que Sergio $Y$. seja uma leitura prazerosa e "delicada," as escolhas feitas pelo escritor devem ser questionadas, especialmente quanto à maneira como fala sobre transexualidade e retrata a função que os gêneros sexuais cumprem socialmente.

De um ponto de vista crítico que se adequa ao contexto em estudo, Vidal Porto pode ser lido como um escritor se aproveitando de um assunto controverso para defender um discurso (hétero)normativo. Ao dar voz apenas ao lado convencional da discussão, perpetua uma distribuição de poder que incentiva o inacabável ciclo do preconceito. No entanto, Sergio $Y$. pode ser interpretado a partir de uma outra perspectiva, segundo a qual o discurso heteronormativo que domina a narrativa é apresentado justamente para ser criticado em função da sua normatividade, conservadorismo e desconhecimento. Assim, o texto é tanto uma tentativa de censurar o leitor tradicional que venha a se identificar com o comportamento conservador dos personagens quanto um retrato fidedigno do pensamento tradicional, pronto para ser criticado veemente por quem apoia as causas LGBTQ.

As contradições discursivas presentes em Sergio $Y$. e a falta de performatividade queer resultam no realce das fronteiras impostas entre os pensamentos heteronormativo e queer. Nas evidências que distanciam os dois mundos se encontram os grandes méritos deste texto. Sozinho, o autor não levanta grandes questionamentos sobre estudos de gênero, especialmente do ponto de vista teórico e político. A maneira como versa sobre um tema ainda

\footnotetext{
${ }^{1}$ Utilizo o termo queer baseando-me na definição proposta por Jagose. Segundo ela, o conceito de identidade queer é definido por uma necessidade de desnaturalizar seu significado, compreendendo que não há um conjunto de características específicas para rotular o que é ser queer, assim contrariando a lógica normativista social. A falta de categorização já é o queer na sua própria essência. Por essa razão, escolhi não grafar a palavra queer com itálico, conforme as regras de estilo acadêmicas que se utilizam dessa ferramenta para salientar o uso de estrangeirismos. Ao não fazer uso do itálico, coloco em prática o preceito de existência queer sem qualquer limitação imposta socialmente.
} 
polêmico como a transexualidade pode soar desinformada e condescendente para os especialistas nesta área de estudos e, também, para as minorias sexuais. Entretanto, a omissão do lado performativo queer e também de uma proposta pugnaz contra a discriminação de gênero, pode servir como uma provocação que contribui para repensar de que forma indivíduos trans ainda são (re)tratados na realidade brasileira.

Sendo assim, foco este ensaio na análise da legitimidade do discurso sobre identidade sexual e diáspora queer em Sergio Y., trazendo à tona os questionamentos que podem despontar quanto ao tratamento que a sociedade heteronormativa oferece ao público LGBTQ, em especial aos transexuais. ${ }^{2}$ Para discutir a (trans)formação do sujeito trans e como ele está inserido na sociedade, analiso alguns dos assuntos recorrentes em Sergio Y., tal qual a influência da heteronormatividade na voz narrativa, a ideia da imigração como uma metáfora para a libertação das identidades sexuais e, também, a exposição (ou invisibilização) do pensamento queer. A partir da minha leitura, espero colaborar para a abertura do espaço de diálogo que promova a inserção social da comunidade transexual, contribuindo para o fim de uma política de medo, ignorância e transfobia.

Publicado em 2014, Sergio Y. vai à América é uma história centrada, a princípio, em dois personagens: Armando e Sergio. Armando é um psiquiatra que recebe a indicação de um novo paciente através de uma antiga colega de faculdade que agora é diretora de um tradicional colégio paulista. Sergio é um adolescente que vai parar no seu consultório na tentativa de, em suas próprias

\footnotetext{
${ }^{2}$ Ao contrário de outros países, como os Estados Unidos, onde o termo "transgender" é usado para pessoas que não se identificam com a identidade de gênero que lhes foi atribuída ao nascer, e "transsexual" para o indivíduo que passa pelo processo de transformação de um sexo para outro, no Brasil essas distinções ainda não são usadas com tanta clareza. Logo, os termos transgênero e transexual ainda costumam ser utilizados como sinônimos para todos os indivíduos "trans," independentemente de terem passado pelo tratamento/cirurgia de mudança de sexo ou não. No caso de Sergio Y., as duas situações estão presentes: primeiro, Sergio não se identifica como masculino (transgênero); depois, em Nova York, assume o nome de Sandra e inicia um processo de transformação que culmina na cirurgia (transexual). Há também a complicação da tradução dos termos "transsexuality" que se torna "transexualidade," enquanto "transgenderism" não tem um equivalente, sendo às vezes mal traduzido como "transgênico." Desta forma, utilizarei os termos transgênero, transexual e trans ao longo de este ensaio, mas me limitarei à transexualidade.
} 
palavras, "garantir um futuro minimamente feliz" (22). Através da relação médico e paciente-que não é muito longa, mas mesmo assim é significativase descobre mais sobre a natureza oposta desses dois personagens.

Apesar do título da história ser Sergio Y. vai à América, os acontecimentos são narrados por Armando. Sergio é a figura titular porque serve como o catalisador para os pensamentos e ações do narrador. De certo modo, o jovem é o responsável por tirar Armando de sua zona de conforto. É ele quem entra na vida do médico e não o contrário. $\mathrm{O}$ impacto da presença (e futura ausência) de Sergio é o que faz com que Armando se sinta impelido a narrar a história sobre o paciente que foi assassinado depois de ir morar em Nova York para "assumir" a sua identidade transexual como Sandra. ${ }^{3}$

Sabendo que a narrativa gira em torno da transexualidade de Sergio (algo que o leitor sem informações prévias sobre a trama descobrirá apenas após a morte do personagem), seria lógico que Vidal Porto colocasse a voz do personagem como foco principal do texto. No entanto, é Armando quem dá o tom ao discurso, até quando se trata de falar sobre o que é ser trans. Pouco se ouve sobre as considerações de Sergio sobre o assunto. Poucas são as aspas que sinalizam a sua intervenção no que Armando narra. O seu testemunho é verbalizado através das lembranças do psiquiatra. Aqui encontro a zona de conflito em Sergio Y. vai à América: por que eleger um narrador cujo único contato com a transexualidade é o paciente que considera um "passivo a descoberto" (46), um caso que ficou sem solução, uma vez que o médico tem a sensação de que falhou com Sergio ao não ter visto qualquer indício de transexualidade no jovem? Como pode um narrador que se enquadra em todos os padrões heteronormativos ser responsável por discutir sobre a definição da

\footnotetext{
${ }^{3}$ Neste ponto é possível fazer uma das primeiras críticas aos comentários que Armando faz sobre as identidades trans. O psiquiatra descreve o processo de Sergio se "transformando" em Sandra, como uma escolha e não como uma questão mais profunda de identificação. Assim, as falas de Armando focam mais no lado visual/biológico da transição do personagem do que nos efeitos psicológicos e nos conflitos que Sergio sentia quando não podia "ser" Sandra, um erro ainda maior sendo ele psiquiatra. Armando ignora que o seu paciente se "assumia" como Sergio em função das expectativas sociais, mas na verdade Sergio é quem nunca existiu, Sandra é quem sempre foi real. Apesar de reconhecer Sandra como a personagem central do livro, manterei a distinção feita pelo autor (entre Sergio e Sandra) para tentar manter a uniformidade com o pensamento presente no livro, assim sendo possível criticá-lo com mais clareza, evitando possíveis confusões entre o meu discurso e o do autor.
} 
identidade de um indivíduo transgênero, ainda mais sabendo que este é um tópico que nunca foi examinado (e nem ao menos percebido) durante as sessões de terapia?

No momento em que Armando se apresenta, é possível entender em qual viagem discursiva o leitor está prestes a embarcar. O psicanalista se descreve como um homem de 70 anos que sempre aparentou ser mais velho do que a sua idade real. Seu envelhecimento precoce pode ser justificado por sua profissão, uma vez que os psiquiatras "absorvem os problemas dos pacientes. Envelhecemos por eles" (11). Armando é o que se espera de um membro exemplar da sociedade. É a personificação da heteronormatividade que contrasta com a transexualidade de Sergio. De um ponto de vista heteronormativo, tal qual examino a seguir, Armando e Sergio são opostos. O médico goza de seu privilégio de psiquiatra bem-resolvido e bem-sucedido, cuja vida seguiu os padrões esperados pela sociedade, enquanto Sergio, mesmo antes de assumir ser transexual e "tornar-se Sandra," é descrito como um jovem de dezessete anos "articulado, inteligente, confuso" (17; ênfase minha). O modo como os dois personagens se contrapõem ajuda a criar uma ideia binarista-juventude versus velhice, instabilidade versus equilíbrio, transgressão versus tradição-que é comum em uma sociedade acostumada a impor regras para classificar o que são comportamentos padrões e quais são transgressores.

O mundo interior que Armando habita é construído em preto e branco. Já o que se passa dentro de Sergio é um caleidoscópio de cores infinitas, um "caso interessante" (17), difícil de definir do ponto de vista socionormativo representado por Armando. Essa diferença, mesmo que não declarada abertamente, está associada ao confronto de outro binário, tradição versus exotismo, sendo o segundo uma característica frequentemente explorada em retratos LGBTQ. ${ }^{4}$

Ao fazer o resgate de seu histórico familiar, o narrador fornece mais indícios do seu estilo de vida conservador. A maneira como apresenta os membros da sua família, principalmente a atenção que dá ao pai, contrasta com o tratamento dado

\footnotetext{
${ }^{4}$ Apesar da impossibilidade de definir o que seria literatura queer, há uma associação direta do termo com o conteúdo de textos literários que trabalham com personagens LGBTQ. Duas obras célebres da literatura brasileira que costumam ser vinculadas à literatura queer ou literatura LGBTQ são Morangos mofados (1982), de Caio Fernando de Abreu, e Stella Manhattan (1985), de Silviano Santiago.
} 
à figura materna. Seu pai também era médico e serviu como modelo para as escolhas futuras do filho. Pouco tempo depois da morte paterna prematura em um acidente de carro, Armando entra na Faculdade de Medicina, sempre desempenhando o papel de melhor aluno da classe, aquele com um futuro promissor, que vai fazer residência nos Estados Unidos e se dedica de corpo e alma a sua vocação. Ele não se desvia do caminho que é traçado para os "homens convencionais" mesmo antes de nascer. A imagem de filho que se espelha no pai- "Quando encontrávamos pessoas que o conheciam, eu me orgulhava do respeito e da deferência com que o tratavam" (12) — e que segue seus passos"Queria ser médico como ele. Cresci idolatrando-o" (12)-traduz em realidade as concepções enraizadas nos princípios heteronormativos que definem o papel da identidade masculina na sociedade. Judith Butler recorre ao trabalho de LéviStrauss para recuperar essa construção ancestral do ideal masculino:

For Lévi-Strauss, the masculine cultural identity is established through an overt act of differentiation between patrilineal class, where the "difference" in this relation is Hegelian-that is, one which simultaneously distinguishes and binds. But the "difference" established between men and the women who effect the differentiation between men eludes the dialectic altogether. In other words, the differentiating moment of social exchange appears to be a social bond between masculine terms that are simultaneously specified and individualized. On an abstract level, this is identity-in-difference, since both clans retain a similar identity: male, patriarchal, and patrilineal. Bearing different names, they particularize themselves within this all-encompassing masculine cultural identity. (54)

Butler enfatiza a busca pela diferença como forma de individualização dos binários sociais, possibilitando a distribuição do poder social. Como é de se esperar, a sociedade tradicional dominante segue modelos convencionais de comportamento nos quais o papel dos indivíduos de diferentes gênerosfocalizado apenas no binário homem/mulher, já que as demais formatações de identidade sexual são "subversivas" e por isso marginalizadas - é diferenciado pelo pensamento patriarcal (a superioridade masculina) e pela patrilinearidade (o reconhecimento do indivíduo através da herança deixada pelo pai e não pela 
mãe). Estes dois conceitos contribuem para a criação de discursos como o da heteronormatividade, servindo para explicar porque as mulheres têm um papel tão pequeno na vida de Armando. Considerando o histórico familiar do narrador, enquanto o pai é descrito como alguém digno de idolatria, a mãe tem uma função diminuta na formação da identidade do filho. Armando se vangloria do homem que o pai foi e como ele foi essencial para que o psicanalista se tornasse o homem que diz ser. Já a mãe é descrita de uma maneira rasa, sem que sua existência individual tenha grande impacto, tanto no macrocosmo (sociedade) quanto no microcosmo (o filho), leitura compreendida através da visão de Iris Marion Young:

The culture and society in which the female person dwells defines woman as Other, as the inessential correlate to man, as mere object and immanence. Woman is thereby both culturally and socially denied the subjectivity, autonomy, and creativity that are definitive of being human and that in patriarchal society are accorded the man. At the same time, however, because she is a human existence, the female person necessarily is a subjectivity and transcendence, and she knows herself to be. The female person who enacts the existence of women in patriarchal society must therefore live a contradiction: as human she is a free subject who participates in transcendence, but her situation as a woman denies her that subjectivity and transcendence. (31-32)

Do ponto de vista de Young, a separação - tal qual a diferenciação utilizada por Butler-serve para colocar a mulher em um papel de isolamento (otherness como um conceito de alienação).

"Meu pai, Miguel, foi o primeiro namorado de minha mãe, Ondina" (13). Essa é a primeira referência que Armando faz a sua mãe. O existir feminino está ligado ao homem, depende dele de um ponto de vista normativo porque não há possibilidade de transcendência para a mulher. Sem o indivíduo masculino, não há identidade feminina. ${ }^{5} \mathrm{O}$ homem tem uma existência independente e a mulher apenas coexiste na estrutura social em que Armando vive. O narrador prossegue

\footnotetext{
${ }^{5} \mathrm{O}$ narrador repete essa mesma projeção na relação Sergio-Sandra. Do ponto de vista do narrador, Sandra só existe a partir da "permissão" de Sergio.
} 
com a descrição de sua mãe como "viúva" e "irmã," mais dois substantivos que renegam a individualidade da mulher — a viúva depende do marido para existir e a dependência é permanente até depois da separação imposta pela morte, já a irmã depende da manutenção da estrutura familiar tradicional—ou seja, o papel feminino fica restrito ao ambiente familiar patriarcal, impossibilitado de alçar voos e desencadear os feitos que as figuras masculinas inspiram. Butler se utiliza dos pensamentos de Luci Irigaray na intenção de compreender quais são os mecanismos utilizados socialmente para definir-se o que distingue homem e mulher:

As Irigaray argues, this phallogocentric economy depends essentially on an economy of différance that is never manifest, but always both presupposed and disavowed. In effect, the relations among patrilineal clans are based in homosocial desire (what Irigaray punningly calls "hommo-sexuality"), a repressed and, hence, disparaged sexuality, a relationship between men which is, finally, about the bonds of men, but which takes place through the heterosexual exchange and distribution of women. (55)

O conceito de falogocentrismo mencionado por Butler e Irigaray e criado por Jacques Derrida também ajuda a perceber a heteronormatividade social representada por Armando. Discursos normativos não apenas estão centrados em ideais falocêntricos — o empoderamento da identidade masculina ligada à posse do falo-mas também creditam ao falo(logo)centrismo a monopolização do conhecimento nas mãos masculinas. Assim o pai é o médico/ídolo e a mãe é somente a namorada/viúva do pai, títulos com pesos bem distintos levando em conta a valoração atribuída a cada um deles quando se busca definir quem está no comando.

É na noção falogocêntrica enraizada no discurso heteronormativo que encontro uma justificativa para Armando ser o narrador da trama. A presença do pênis ligada à posse do conhecimento faz com que Armando seja mais "sábio" do que Sergio, um rapaz que passa pela cirurgia de mudança de sexo e assume sua identidade feminina. Ao remover o falo, Sergio renuncia ao (re)conhecimento do discurso heteronormativo que está em julgamento na história e assume sua posição de "outro" atribuída à identidade feminina. Em 
função da transexualidade, Sergio ocupa uma posição de inferioridade social. A transexualidade o impede de ser dotado de uma noção empoderadora ligada à masculinidade e, por isso, o coloca no lugar de subordinado na escala dicotômica entre homens e mulheres. Em outras palavras, a estrutura social em que Armando se localiza é masculina, já Sergio rompe com essa estrutura tradicional porque se identifica como Sandra, vivenciando uma existência feminina que não pode liderar a propagação heteronormativa do pensamento falogocêntrico.

A caracterização do patriarcado, da patriliniaridade e do falogocentrismo que conduz o discurso normativo tal qual aplicado na relação entre Armando e seus pais fica ainda mais proeminente quando ela é contrastada com a ligação entre Sergio e seus progenitores. Armando tem o pai colocado no lugar mais alto (intocável) em uma classificação de influência. Já a mãe está diversos degraus abaixo. Enquanto isso, no histórico familiar de Sergio, a dinâmica é contrária. Há uma tensão entre ele e o pai, fazendo com que a participação paterna na vida do filho seja menor do que a materna. Tal ruptura é nítida em uma das primeiras menções que Armando faz ao pai de Sergio:

O pai de Sergio era um empresário importante. Administrava a cadeia de lojas de eletrodomésticos da família que se espalhava pelo Brasil. Sergio teria condições de viver bem onde bem entendesse e de fazer o que porventura quisesse, mas, como filho único de Salomão Yacoubian, era de esperar que ele fosse viver em São Paulo e cumprir seu destino hereditário nos negócios da família. (52; ênfase minha)

Enquanto Armando seguiu o roteiro de sucessão programado de pai para filho, trilhando a carreira médica, Sergio rompe com os padrões de espelhamento impostos pela tradição patriarcal e patrilinear. Utilizei os grifos na citação anterior justamente para apontar os indícios de quebra com os ideais de perpetuação da linhagem paterna. Armando começa a descrição da figura masculina por seu ofício. A profissão do homem representa seu caráter social, capaz de munir o personagem de uma natureza de superioridade e importância, estipulando o exemplo a ser seguido. Assim começam a ser estabelecidos os parâmetros que Sergio deveria seguir como exemplo: ser um grande homem de negócios, cuidar dos negócios da família, etc. Contudo, contrariando as expectativas normativas, Sergio não cumpre com esses papéis sociais. 
A mesma sociedade que traçou o destino de Sergio é aquela que faz com que estereótipos femininos também se proliferem. Considerando que o narrador foi escolhido para desempenhar a função de representante das normas e bons costumes, julgo interessante analisar a maneira como ele descreve a mãe de Sergio na primeira vez em que eles se encontram:

Senti vontade de observá-la, mas preferi olhar para a vitrine de queijos e evitar aquela mulher de cabelo preto, preso para trás, que usava brincos de brilhantes tão grandes que até eu, que não particularmente atento a joias, os notei. Com os queijos à minha frente, pensava na obviedade com a qual ela exibia sua riqueza. Estava lá: o estereótipo feminino de uma categoria de gente que eu conhecia muito bem do meu consultório. (49; ênfase minha)

Saliento a diferença entre empresário importante e aquela mulher, expressões corriqueiras no discurso patriarcal e que empoderam o homem e denigrem a mulher. O narrador ainda usa o termo estereótipo feminino com se fizesse uma crítica ao feminino. No entanto, o que pode passar desapercebido é que ele é parte da estereotipização que critica. Armando é uma caricatura do homem normativo e ao cumprir o seu papel está perpetuando os mesmos clichês presentes nos arquétipos sociais que ele quer criticar.

Há mais um choque entre o prestígio masculino e a depreciação feminina quando retomamos a primeira consulta de Sergio com Armando. O psiquiatra faz suas primeiras considerações sobre a família do jovem: "Reconheci o sobrenome e deduzi que ele fosse filho de quem era mesmo. Conhecia seu pai de nome. À época, porém, não sabia que seu cabelo negro e liso era como o de sua mãe" (22; ênfase minha). O reconhecimento imediato do sobrenome e a conexão com a autoridade que ele carrega demonstram a força da patrilinearidade. Filho de quem era enfatiza a valorização atribuída à herança paterna. O sobrenome paterno carrega o peso do interesse e prestígio masculino, mesmo não passando de uma criação social subjetiva utilizada para associar pessoas com heranças familiares patriarcais. Já o legado da mulher está restrito ao corpo como um objeto de desejo e de procriação. Anteriormente, Armando sentia vontade de observar a mãe de Sergio, restringindo a mulher à posição de acessório. Depois a única associação 
que faz entre mãe e filho são traços físicos, como o cabelo. Tais formas de se referir ao espólio da mulher objetificam o corpo e a identidade feminina:

This objectified bodily existence accounts for the self-consciousness of the feminine relation to her body and resulting distance she takes from her body. As human, she is a transcendence and subjectivity and cannot live herself as mere bodily object. Thus, to the degree that she does live herself as mere body, she cannot be in unity with herself but must take a distance from and exist in discontinuity with her body. (Young 44)

Young explica o conflito imposto pela sociedade patriarcal que cria à necessidade de (tentar) dissociar o corpo de um objeto, fazendo com que a mulher procure subterfúgios para transcender o estereótipo. Os brincos de brilhantes utilizados pela mãe de Sergio, por exemplo, podem ser vistos como uma dessas artimanhas femininas para que o corpo se torne subjetivo. Com a atração causada pelos brincos, a violência presente na atenção do olhar masculino sobre o corpo feminino é desviada, sem que para isso a mulher tenha que abrir mão de sua feminilidade, o que geraria outra rachadura na base da estrutura social machista.

Voltando à ligação entre pai e filho, o fato de Sergio ser filho único também aumenta o nível de responsabilidade quanto à continuação do legado paterno. Armando descreve bem o conflito em que Sergio se encontra por causa da posição social ocupada por sua família ao dizer que "Sergio teria condições de viver bem onde bem entendesse e de fazer o que porventura quisesse" (52; ênfase minha). ${ }^{6}$ No entanto, no sistema patriarcal, o filho único não tem direito a ter desejos que não estejam alinhados com o ciclo de sua descendência masculina. O avô de Sergio, Hagop Yacoubian, veio para o Brasil e começou o negócio da família. Depois foi sucedido pelo filho, Salomão Yacoubian. Logicamente Sergio Yacoubian deveria suceder o pai, completando o destino hereditário. Exceto que não é isso o que ocorre. No caso de Sergio, a ruptura é ainda mais severa porque ele é o filho que sobreviveu. Apesar dessa responsabilidade, ele renega o patrimônio masculino, tanto de um ponto de vista econômico quanto emocional e físico. O pai de Sergio enxerga a futura interrupção da linhagem da família

\footnotetext{
${ }^{6}$ A escolha de palavras de Armando mais uma vez salienta o falso entendimento de que transexualidade seria uma questão de escolha.
} 
Yacoubian no seu legado paterno: "Eu gerei duas monstruosidades: um anencéfalo e um transexual" (155). Essa afirmação dotada de culpa e mágoa demonstra como a trajetória de transformação de Sergio para Sandra desestabiliza a estrutura tradicional da família, deixando transparecer as áreas de tensão que acompanham o tema da transexualidade.

Depois de analisar as exigências impostas pelo discurso heteronormativo presente no ambiente em que Sergio nasceu, é possível compreender a "confusão" que havia dentro do jovem. Sandra não quer ser apagada para cumprir com o plano familiar que lhe foi traçado, mas ao deixar de ser Sergio, ela estaria dando fim à linhagem patriarcal. Logo, para que Sandra pudesse existir, Sergio precisava romper com essas amarras, abrindo mão de uma responsabilidade social que ele não havia pedido. Então, como "era de se esperar que ele fosse viver em São Paulo" (52), a única saída viável para violar as obrigações patriarcais é mudar de país.

O assunto da imigração em Sergio Y. vai à América é abordado não apenas a partir de uma noção física e geográfica, mas também como uma metáfora que permite a formação de "novas" identidades sexuais. Sergio queria "abandonar o lugar em que vivia para continuar vivendo" (67). A frase que Armando encontra quando revisa as anotações feitas durante as consultas resume a maneira como a mudança para um país distante da patrilinearidade sufocante pode representar a possibilidade de recomeço e libertação para quem está disposto a romper com a normatividade social.

No entanto, há um paradoxo na situação vivida por Sergio. A esperança de vida nova faz com que o desejo de mudança seja epifânico, mas o abandono do lugar de nascimento também enfatiza a existência de uma identidade em deslocamento (e talvez "sem lugar"). Da mesma maneira como a imigração representa a abertura de novos horizontes (uma vivência queer), também faz com que os personagens (trans)formem suas identidades sociais e sexuais através do apagamento de um passado que possivelmente não possa conviver com o presente. Ao abdicar de São Paulo, Sandra pode tomar o lugar que é verdadeiramente seu. Mas o que ocorre com Sergio? Existe uma coexistência entre Sandra e Sergio em Nova York, ou Sandra passa a existir apenas a partir da invisibilização de Sergio? A disputa entre a identidade social (Sergio) e a identidade trans (Sandra) faz com que seja impossível para Sandra também existir em São Paulo? Se existe um apagamento identitário ligado à 
transexualidade, trata-se de uma escolha individual, de uma imposição coletiva, ou de ambos?

Halberstam discute a existência de espaços e lugares que representam os indivíduos que se identificam com uma identidade queer, como é o caso de Sergio/Sandra. Retomo as expectativas que sobrecarregavam Sergio em relação à sua história familiar: "era de esperar que ele fosse viver em São Paulo e cumprir seu destino hereditário nos negócios da família" (52). Dentro da construção de espaço concebida por Vidal Porto, existem dois cenários sendo habitados: São Paulo e Nova York. Considerando que a cidade brasileira é a terra natal de Sergio, logicamente está ligada a todos os preceitos heteronormativos com os quais ele terá que romper para poder viver como Sandra. Halberstam explica que "queer uses of time and space develop, at least in part, in opposition to the institutions of family, heterosexuality and reproduction" (1). Nesse ínterim, caso Sergio escolhesse ficar no Brasil estaria silenciando Sandra e se submetendo aos valores que negam a sua identidade. Para evitar esse desfecho, ele opta pela mudança para outra localidade, que parece ser mais receptiva e queer.

A imigração tem um caráter radical que força a mudança interna dos personagens e por isso pode soar como uma alternativa extremista para um problema que poderia ser "solucionado" com o silêncio. Inclusive, para o olhar (hétero)normativo, o silenciamento da identidade transexual não é visto como um problema, e sim como a conduta adequada para que a estrutura social tradicional não seja perturbada. Assim como a imigração está associada à libertação, a invisibilidade queer é a resposta imediata do coletivo heteronormativo para o "problema" das identidades sexuais não-binárias.

Quando o indivíduo trans não invisibiliza sua identidade queer, o coletivo impõe a ele uma existência marginal. Em Sergio Y. vai à América, a única exposição direta da violência contra os transexuais é vista no assassinato de Sandra. Os demais atos de preconceito fazem parte de um discurso velado. Até mesmo Armando admite que dentro do discurso heteronormativo, a marginalização e a violência são concebidas como respostas sociais naturais, e são impostas a partir da escolha transgressiva do indivíduo. “À época, não compreendia que, sem perceber, reproduzia no meu entendimento o estereótipo de que a morte de um transexual é sempre causada pela tragicidade de sua própria vida" (75). Qualquer ato violento contra a vida trans é resultado das decisões do 
transexual, em um jogo de ação e reação em que quem dá as cartas continua a ser o status quo heteronormativista.

Um fato que pode passar despercebido e que contribui para a ideia da invisibilização dos personagens transexuais é que a negação da transexualidade se manifesta antes mesmo de que questões de gênero sejam abordadas de forma direta. A transexualidade de Sergio, por exemplo, é invisibilizada antes que ele admita ter o desejo de mudar de sexo. O silenciamento pode ser percebido no momento em que Armando está contando sobre as sessões de terapia que teve com o rapaz. Os personagens estão presentes em um espaço de tempo anterior a qualquer conhecimento sobre o futuro de (trans)formações reservadas ao adolescente:

Nas nossas sessões, falava da expectativa dos pais em relação a ele e de sua indefinição vocacional. Considerava-se 'difícil de fazer amigos.' Às vezes, mencionava uma colega de escola chamada Sandra, por quem, aparentemente, nutria sentimentos platônicos. Contou-me que 'admirava sua maneira de ser.' Quando perguntei se gostaria que ela fosse sua namorada, disse que 'tinha coisas mais urgentes na vida para resolver.' (28; ênfase minha)

A escolha de palavras do narrador é interessante neste trecho, uma vez que o uso das aspas deixa claro o que Sergio queria dizer e o que é interpretação de Armando. O psiquiatra fala sobre as expectativas paternas e indefinições vocacionais, duas preocupações de grande importância em um ambiente de educação normativista e patriarcal. Porém, ele acaba ignorando que o vínculo entre expectativas e indefinições se estendia além do campo profissional. Percebo o ápice do discurso heteronormativo no momento em que o médico faz a conexão Sandra / Sentimentos Platônicos / Namorada. Um homem como Armando, modelo fidedigno da sociedade tradicional dominante, mesmo se colocando no papel de profissional exemplar, não consegue pensar além da configuração reducionista em que um adolescente ao mencionar o nome de uma menina confirma o desejo do homem pela mulher. Armando não percebe que a relação platônica entre Sergio e Sandra não existe porque o homem quer ter a mulher, mas sim porque o masculino quer ser o feminino. 
Armando é procurado por Sergio porque o adolescente precisa de ajuda para lidar com os seus conflitos: "Comigo falava mais de sua família que de si próprio. Tenho a impressão de que, ao falar da família, queria expor a história da qual provinha, o enredo do qual fazia parte. Sergio Y. queria se explicar, entender a genealogia de sua infelicidade inelutável, com o objetivo, eu esperava, de superála" (29). A maneira como Sergio passa pelo processo de transição, dando espaço para Sandra, mostra que a sua confusão interna não dizia respeito à própria aceitação de sua transexualidade. A dificuldade encontrada para assumir-se como Sandra era lidar com a reação das outras pessoas, como seus pais e até Armando, a partir do momento em que frustrasse as expectativas que eram reservadas ao seu futuro. A difícil escolha que Sergio deve fazer não é entre Sandra ou ele, mas sim entre Sandra e os demais, entre existir para si mesmo e desaparecer para o coletivo ou invisibilizar-se como indivíduo para manter a ordem social. O conflito que Sergio sentia quanto à questão da invisibilidade é um tema recorrente nas entrevistas que constituem o livro de Girshick, como se pode perceber neste depoimento:

Invisibility is a dangerous and painful condition. [...] When those who have the power to name and socially construct reality choose not to see or hear you, whether you are dark-skinned, old, disabled, female or speak with a different accent or dialect than theirs, when the authority of a teacher, say, describes the world and you are not in it, there is a moment of psychic disequilibrium, as if you looked into a mirror and saw nothing. (111)

A metáfora de se olhar no espelho e não ver nada parece adequada para o que Sergio devia sentir antes de dar visibilidade a Sandra. O processo de visibilização (de aceitação interna) é cercado por interrogações. Por mais que Sergio e Armando tivessem criado vínculos de confiança, vide a gratidão que o paciente demonstra pelo médico, o personagem-título nunca se declara trans para o psicanalista. Ao decidir mudar-se para Nova York, Sergio poupa Sandra de um mundo ao qual ela não pode pertencer sem que haja grandes demonstrações de preconceito e repúdio. Do lugar de onde Sergio vem, o destino reservado a Sandra é a marginalização. Para preservar aquela a quem admirava por sua maneira de ser, Sergio opta por uma espécie de exílio queer. Rosemary 
Marangoly George define a imigração como uma alternativa que "unwrites the nation and national projects because it flagrantly displays a rejection of one national space for another more desirable location, albeit with some luggage carried over" (83). Sandra carrega consigo as marcas deixadas por Sergio, tanto físicas quanto emocionais. No entanto, para o transexual, mais difícil do que a dor física gerada pelo processo de transição é conviver com o olhar heteronormativo do outro que viola sua identidade ao delimitar as possibilidades de ser quem realmente se quer ser.

$\mathrm{O}$ posicionamento de Armando quanto à mudança de sexo de Sergio é contraditório em diversos momentos do texto. Apesar do psicanalista tentar passar um ar de compreensão, sua atitude (repleta de omissões e interpretações deturpadas) em alguns momentos traz indícios de preconceito dissimulado e em outros de pura ignorância ${ }^{7}$. Mesmo depois de demonstrar uma dedicação ferrenha para entender o que aconteceu com seu antigo paciente - "Senti-me obrigado a reler todas as notas e ouvir todas as gravações das sessões com Sergio. Nosso ano de análise tinha rendido um caderno de capa verde e vários arquivos de computador" (67) - Armando não lembra da conversa que teve com Sergio na qual o nome de Sandra foi mencionado. O esquecimento do psicanalista pode ser interpretado como uma tentativa de omissão, seja por orgulho, seja por incapacidade profissional e/ou emocional.

Entre as zonas de conflito criadas pelo narrador, a maneira como ele insiste em dissociar Sergio de Sandra é uma das formas mais latentes de mostrar como o preconceito contra a transexualidade pode estar contido em pequenas atitudes disfarçadas de boas intenções. Ao retraçar os passos de Sergio, Armando encontra outras pessoas. Esses personagens secundários são dotados de um papel essencial para a utilidade educacional de Sergio Y. vai à América. Da mesma maneira como Vidal Porto dividiu o espaço de Sergio/Sandra em dois (São Paulo como o heteronormativo e Nova York como o queer), os sujeitos são separados

\footnotetext{
${ }^{7}$ A citação de E.M. Forster que é utilizada por Vidal Porto na abertura de Sergio $Y$ ilustra a vaidade que cega Armando, de forma que seja difícil definer qual é a real intenção de seu comportamento: "Nossa vaidade é tanta que mantemos nossos próprios personagens imutáveis, e nós somos lentos para reconhecer que eles mudaram, até mesmo para melhor."
} 
com a mesma dicotomia: os que invisibilizam Sandra (Armando e os pais de Sergio) e os que dão voz a ela e (re)afirmam a sua existência.

Um dos primeiros momentos em que o leitor é confrontado com a existência real de Sandra é quando Armando contrata um advogado para ajudar na busca de informações sobre a morte de "Sergio" em Nova York. ${ }^{8}$ Esse personagem é responsável por fazer com que Armando tome ciência do que ocorreu com seu antigo paciente. Ele explica:

De todas as informações que Hoskings me passou, os únicos dados que não faziam sentido eram o primeiro nome (Sandra) e o sexo (feminino) da vítima do assassinato em Grove Street, em 2 de fevereiro de 2010. A narrativa que meu advogado americano conseguira produzir de sua pesquisa junto ao sistema judiciário era a seguinte: 'Sandra Yacoubian, nascida em São Paulo, Brasil, em 10 de janeiro de 1988, fora encontrada pela diarista brasileira Edna Alves, morta, de bruços, numa poça do seu próprio sangue. Sandra fora empurrada do quarto andar pela vizinha. Caíra, quebrara o pescoço e morrera exangue no pátio do quintal da casa que dividia com sua assassina no número 12 de Grove Street.' (65)

A partir do momento em que a verdade foi revelada para Armando, era de se esperar que sua atitude, tal qual a de um homem livre de preconceitos como ele tenta se mostrar, fosse a de aceitar a existência e escolhas de Sandra. No entanto, Armando não se desvia do seu discurso heteronormativo. Mesmo sabendo que não há "Sergio," o psiquiatra insiste em se referir à personagem por este nome. O que pode parecer uma formalidade, na verdade é um forte indício da tentativa de apagar a presença de Sandra. A insistência em manter o nome dado pelos pais gera uma série de contradições, como no momento em que Armando visita o cemitério: "Fui duas vezes ao cemitério visitar seu túmulo. 'Sergio Emílio Yacoubian, 10/01/1988-02/02/2011' é o que consta. Sandra não deixou registro de sua breve vida naquela lápide. Sandra nasceu Sergio e permaneceu Sergio depois de morta" (72). Com essa fala, Armando comprova a força do discurso

\footnotetext{
${ }^{8}$ A partir de agora, acrescento aspas ao nome para salientar os trechos em que está claro que a personagem principal é Sandra, enquanto Sergio continua a ser apenas um produto fictício das interações sociais normativas representadas especialmente por Armando.
} 
heteronormativo. Enquanto para o mundo queer que "Sergio" encontrou em Nova York não há registro de outra pessoa morta no dia 2 de fevereiro de 2011 além de Sandra, em São Paulo a lápide diz o contrário. O texto, provável criação da família de "Sergio," nega a sua identidade transexual, baseando-se em uma crença reiterada por Armando segundo a qual a identidade do sujeito é definida pelos órgãos sexuais que são identificados no nascimento ("Sandra nasceu Sergio"), não pela maneira como o indivíduo vê a si mesmo (retomando a ideia do espelho).

Conforme o tempo passa e Armando se envolve com a história de Sandra, fica mais evidente o seu desconforto com a não-existência de "Sergio." Um dos momentos em que o preconceito de Armando se manifesta de maneira clara é quando um segundo olhar clínico entra na história. A inserção da psiquiatra com quem Sandra se tratou, Cecilia Coutts, faz o contraponto entre a visão normativista de Armando e um olhar livre de julgamentos. De maneira quase imperceptível, pela primeira vez Armando se sente obrigado a encarar sua "dificuldade" para aceitar a mudança de nome da paciente. Ele conta:

Tive a presença de espírito suficiente para não demonstrar que ainda estranhava a mudança de nome do nosso paciente. No entanto, sentia certo desconforto, que, racionalmente, tentava superar. Policiava-me para não me referir a Sergio, e sim a Sandra. Para mim, era quase como falar em código. (104; ênfase minha)

O que Armando chama de presença de espírito, chamo de preconceito subentendido. A escolha de palavras do psiquiatra neste trecho, conforme sinalizo na citação, mostra um jogo tramado para disfarçar a intolerância heteronormativa. Armando não fala abertamente sobre como se sente quanto à transexualidade de "Sergio," mas dá indícios através das escolhas de vocabulário que sutilmente substituem o discurso sectarista ostensivo por uma fala coibida pelo politicamente correto. Ele precisa racionalizar o seu discurso para não deixar que emoções tomem conta e a verdade seja revelada, mostrando abertamente sua falta de compreensão sobre o assunto. Ao mesmo tempo, ao contar o que ocorreu e como teve que se controlar para não transparecer a sua vergonha, Armando volta a se referir a Sandra usando pronomes masculinos, "o nosso paciente." 
Logo, mesmo depois de autoavaliar sua conduta discriminatória, Armando comete os mesmos erros.

$\mathrm{Na}$ tentativa de expiar a culpa que carrega tanto como médico quanto como homem normativo, o psiquiatra insiste que em momento algum percebeu qualquer indício de transexualidade em "Sergio." Cabe à psiquiatra de Sandra ser responsável mais uma vez por confrontar o discurso de Armando com a verdade: "Segundo Cecília Coutts, Sandra era um caso inequívoco de disforia sexual. 'Era um caso característico. $\mathrm{O}$ mais notável era que ela demonstrava entendimento não conflitivo de seu quadro clínico. Aceitava-se bem como fenômeno humano e fenômeno médico" (104; ênfase minha). Mais uma vez somos lembrados que o problema quanto à aceitação de Sandra como uma pessoa trans não existia dentro de "Sergio," mas sim naqueles que a cercavam. Ao afirmar que Sandra era um caso característico de disforia sexual, a psiquiatra também desmente outra desculpa utilizada por Armando para justificar a sua ignorância quanto à transexualidade da paciente. Ele defendia sua obsessão por "Sergio" porque "o" considerava um caso em que tinha falhado por nunca ter percebido qualquer sinal de questionamento "do" jovem quanto à sua identidade sexual. Ao insistir que não havia indícios trans em "Sergio," Armando se coloca em uma posição passível de julgamento: o não ver sinais prova sua incompetência profissional (e pessoal) ou a sua recusa a atender (e aceitar) uma pessoa transexual?

Com o encontro entre os dois psiquiatras, as armadilhas discursivas utilizadas por Armando para dissimular sua ideologia heteronormativa começam a ser derrubadas. Ele tinha que se policiar para usar o nome feminino, enquanto a psiquiatra o faz de forma natural. Armando nunca entendeu a condição médica de "Sergio," já Cecília via cada uma das características de disforia sexual em Sandra. Completando o ciclo do preconceito de Armando, ele se sente incapaz de admitir seu "desconhecimento" para Coutts. No entanto, ao invés de declarar abertamente o seu obscurantismo, mais uma vez ele disfarça os seus motivos, primeiro usando o lado profissional - "minha vaidade me impedira de mostrar minha ignorância" (108) — e depois o lado homem — "fiquei intimidado por sua beleza" (108). Com esses subterfúgios, Armando tenta se manter no controle da situação, desmerecendo a figura médica feminina, reduzindo-a a mais um objeto sexual (o que explica a fixação de Armando pela blusa e os seios da médica), e reforçando o seu lado machista dominante que é constantemente legitimado pelo desejo heteronormativo. 
A partir dos exemplos que utilizei para ilustrar meu estudo, e muitos outros que podem ser encontrados na obra, é percetível como Sergio Y. vai à América não dá voz ao público transexual e também não discursa sobre o que é a transexualidade. Apesar dessa falha a princípio imperdoável, pode-se perceber também que o texto de Vidal Porto pode ser lido como uma narrativa que ensina a pensar e a questionar o funcionamento do pensamento (hétero)normativista que invisibiliza e marginaliza a comunidade LGBTQ. Através de Armando, entramos em contato com um retrato fidedigno de uma sociedade heteronormativa, extremamente conservadora e centrada em figuras masculinas, que ainda lida com o tema da transexualidade com medo, preconceito e ignorância, transformando as discussões sobre o assunto em tabus que poucas pessoas se sentem à vontade para quebrar. Se o trabalho do escritor não colabora para o desenvolvimento de políticas e teorias sobre gênero, ao menos funciona como um processo educacional que permite questionar as escolhas não apenas do escritor e seus personagens, mas também de seus leitores.

\section{Obras Citadas}

Butler, Judith. Gender Trouble: Feminism and the Subversion of Identity. Routledge, 1990.

Derrida, Jacques. Writing and Difference. University of Chicago Press, 1978.

Fajardo, Elias. "Resenha de Sergio Y. vai à América." O Globo, 10 de maio de 2014, blogs.oglobo.globo.com/prosa/post/resenha-de-sergio-vai-america-53 5381.html.

George, Rosemary Marangoly. "Traveling Light: Of Immigration, Invisible Suitcases, and Gunny Sacks." diferences, vol. 4, no. 2, 1992, pp. 72-99.

Girshick, Lori B. Transgender Voices: Beyond Women and Men. UP of New England, 2008.

Halberstam, Jack. In a Queer Time and Place: Transgender Bodies, Subcultural Lives. New York UP, 2005.

Vidal Porto, Alexandre. Sergio Y. vai à América. Companhia das Letras, 2014.

Young, Iris Marion. On Female Body Experience: "Throwing Like a Girl” and Other Essays. Oxford UP, 2005. 